\title{
Distribusi dan Kelimpahan Pterapogon kauderni Koumans, 1933 (Apogonidae) di Selat Lembeh Bagian Timur, Kota Bitung
}

\author{
Nathasya sheilla Thiffany Carlos ${ }^{1}$, Ari B. Rondonuwu ${ }^{2}$, Victor N.R. \\ Watung $^{3}$. Fakultas Perikanan dan IImu Kelautan UNSRAT Manado. \\ Email. nathasyast@gmail.com
}

ABSTRACT

This study was aimed at knowing the distribution of Banggai cardinalfish, Pterapogon kauderni, using haphazard survey method. Data collection was done in Lembeh Strait, Mawali, Batu Lubang, and Kareko. The fish found in 3 locations inhabited several habitats, such as anemone, corals, can, garbage, and sea urchin, in which sea urchin Diadema sp., is the habitat outnumbering the other habitats and the most used. The interesting point of this study is the fish were recorded in branching corals, and even there was one site where sufficient number of branching coral colonies was used as the habitat of Pterapogon kauderni. Thus, this study suggested that the distribution of Pterapogon kauderni will follow the natural habitat condition and not be always dependent upon the sea urchin colony.

Keywords : Distribution, habitat, dominance

\begin{abstract}
ABSTRAK
Penelitian ini dilakukan untuk mengetahui distribusi ikan capungan Pterapogon kauderni dengan metode survey jelajah. Pengambilan data penelitian dilakukan di Pulau Lembeh, kelurahan Mawali,Batu Lubang, Kareko. Ikan Pterapogon kauderni yang ditemukan pada 3 lokasi penelitian mendiami beberapa jenis habitat, seperti anemone, karang, kaleng/sampah dan bulu babi genus Diadema sp., yang merupakan habitat yang medominasi dibandingkan dengan habitat lainnya. Hal yang menarik dari penelitian ini adalah ikan Pterapogon kauderni juga teramati di koloni-koloni karang bercabang, dan bahkan di satu lokasi beberapa jumlah koloni karang bercabang yang dijadikan habitat Pterapogon kauderni. Dengan demikian diduga bahwa sebaran populasi Pterapogon kauderni juga akan menyesuaikan dengan kondisi habitat alami yang ada dan tidak akan selalu tergantung pada koloni bulu babi.
\end{abstract}

Kata Kunci : Distribusi, habitat, dominasi

1 Bagian dari skripsi

${ }^{2}$ Mahasiswa Program Studi Agrobisnis Perikanan FPIK-UNSRAT

${ }^{3}$ Staf pengajar Fakultas Perikanan dan IImu Kelautan Universitas Sam Ratulang

\section{PENDAHULUAN}

Pterapogon kauderni (Banggai Cardinal Fish) merupakan salah satu ikan hias air laut yang hidup di daerah lamun dan terumbu karang yang banyak ditemukan mikrohabitat seperti bulu babi, dan anemone. Sejak 1990, Pterapogon kauderni menjadi salah satu ikan hias yang diincar para kolektor dalam dan luar negeri. Karakter yang berbeda dengan ikan Apogonid lain membuat ikan endemik di Banggai Kepulauan, Sulawesi Tengah ini banyak dicari. Diperkirakan 
5.000 ekor ditangkap tiap pekan dan sedikitnya 600-700 ribu ekor diekspor oleh nelayan lokal setiap tahun. Diperkirakan pada tahun 2001-2004, ikan capungan Pterapogon kauderni diperdagangkan mencapai 700-900 ribu ekor tiap tahun. Saat ini, ikan capungan Pterapogon kauderni dapat ditemukan diluar kepulauan Banggai, salah satunya di Selat Lembeh, Sulawesi Utara. Sampai saat ini informasi tentang Pterapogon kauderni di Selat Lembeh masih kurang. Penelitian ini dilakukan untuk menjawab kebutuhan informasi tersebut, meliputi : 1). mengetahui lingkungan perairan; 2). mengetahui distribusi berdasarkan lokasi, kedalaman, dan microhabitat; 3). mengetahui kepadatan relatif (\%) dan kepadatan ikan Pterapogon kauderni di Selat Lembeh per satuan luas.

\section{METODE}

Lokasi pengambilan data penelitian dibagi dalam tiga kelompok penyelam dengan jumlah penyelam 6 orang dan pada kedalaman berbeda. Pengambilan data penelitian oleh masing-masing kelompok penyelam ditentukan searah dengan garis pantai dan menyusuri setiap daerah yang berbeda kedalaman tersebut. Pada saat penyelaman masing-masing penyelam mengamati tipe substrat yang ada seperti substrat pasir, lumpur, dan pecahan karang. Pada setiap substrat yang ditemui diamati habitat dari ikan ini dan dari habitat yang ditemui akan dihitung jumlah individu dari Capungan (BCF) dan mendokumentasikan dalam bentuk foto. Pada masing-masing lokasi pengambilan data dilakukan pengukuran kualitas air dengan menggunakan horibha. Untuk pengukuran kecerahan dilakukan dengan menggunakan secchi disc.

Distribusi dan kelimpahan jumlah ikan capungan akan di hitung dengan menggunakan rumus :
1. Perhitungan kepadatan individu ikan capungan per satuan luas digunakan formulasi :

$$
d=\frac{\mathrm{c}}{\mathrm{A}}
$$

dimana: d=Kepadatan

(Individu/Ha)

c = Jumlah ikan capungan yang terhitung dalam pengamatan

$A=$ Luas daerah pengamatan (Ha);

2. Kepadatan relative (\%) menggunakan rumus dibawah ini :

$$
\begin{aligned}
& \mathrm{KR}(\%)= \\
& \frac{\text { Jumlah individu ke }-\mathrm{i}}{\text { Total individu }} \times 100
\end{aligned}
$$

3. Untuk melihat apakah satu tipe habitat Standar Deviasi satu teknik statistik yg digunakan untuk menjelaskan homogenitas kelompok. Standar Deviasi merupakan variasi sebaran data. Semakin kecil nilai sebarannya berarti variasi nilai data makin sama. Jika sebarannya bernilai 0 , maka nilai semua datanya adalah sama. Semakin besar nilai sebarannya berarti data semakin bervariasi.

$$
S=\sqrt{\sum \frac{\left(x_{1}-\bar{x}\right)^{2}}{n}}
$$

Dimana:

$\mathrm{x}=$ data ke $\mathrm{n} . /$

$\mathrm{x}$ bar $=\mathrm{x}$ rata-rata $=$ nilai rata-rata sampel $\mathrm{n}=$ banyaknya data

\section{HASIL DAN PEMBAHASAN}

\section{Lingkungan Perairan}

Secara umum, semua parameter lingkungan perairan di Selat Lembah Bagian Timur (Pulau Lembeh) berada pada kisaran normal. Artinya, 
lingkungan perairan Selat lembeh pada umumnya sangat mendukung kehidupan dan perkembangan ikan capungan Pterapogon kauderni.

Menurut Ndobe (2011), ikan capungan hidup di kisaran $\mathrm{pH} 8,1$ hingga 8,4 dan nilai kisaran ini hampir sama dengan 3 lokasi penelitian di Selat Lembeh ( $\mathrm{pH}: 8,16-8,34)$. Nilai $\mathrm{pH}$ yang relatif normal ini bisa disebabkan kurangnya bahan organik dari daratan yang sifatnya asam, kalaupun ada mungkin sangat kecil. Bila ada bahan organik yang masuk dari daratan atau disumbangkan oleh kegiatan pemukiman (rumah tangga) akan dapat terlihat dari rendahnya $\mathrm{pH}$. Bila dibandingkan dengan nilai baku mutu air laut $(33-34 \%)$ maka kadar salinitas di selat lembeh juga masih dalam kisaran sempit $(32,24-32,42)$ masih berada pada kisaran yang alami. Dengan kandungan oksigen terlarut di perairan pulau Lembeh 13,66 - 15,71 $\mathrm{mg} / \mathrm{l}$, menunjukkan bahwa proses metabolisme, pernapasan dan pertumbuhan biota di dalamnya termasuk ikan capungan Pterapogon kauderni masih sangat baik. Makin besar turbidity dan padatan tersuspensi akan dikuti oleh makin berkurangnya kecerahan air. Data hasil pengukuran turbidity di Selat Lembeh pada umumnya masih jauh dibawah batas toleransi. Kondisi ini juga berbanding terbalik dengan tingkat kecerahan yang masih relative tinggi di atas 19 meter.

\section{Distribusi dan Kelimpahan}

Ikan capungan Pterapogon kauderni tersebar di sepanjang wilayah terumbu karang Selat Lembeh Bagian Timur (Pulau Lembeh) khususnya pada tiga lokasi yaitu Kelurahan Kereko, Mawali, dan Kelurahan Batu Lubang. 5 jenis mikro habitat yang ditempati oleh ikan capungan Pterapogon kauderni meliputi bulu babi, anemon, karang bercabang, pasir dan hancuran karang, sampah kaleng, dan dua jenis habitat hanya ditemukan di satu lokasi
(Kareko) yaitu pasir dan hancuran karang, dan sampah kaleng.

Dasar permukaan/substrat yang ditempati populasi ikan capungan Pterapogon kauderni terlihat ada perbedaaan antara lokasi di Kelurahan Kareko yang bervariasi meliputi karang batu, pasir, dan lumpur dengan 2 lokasi lainnya yaitu Kelurahan Mawali dan kelurahan Batu Lubang yang banyak didominasi oleh pasir dan hancuran karang.

Populasi ikan capungan Pterapogon kauderni yang ditemukan di sepanjang wilayah terumbu karang Selat Lembeh Bagian Timur dalam jumlah individu yang bervariasi baik terhadap lokasi maupun habitatnya. Populasi tertinggi ditemukan di Kelurahan Mawali yaitu 921 individu diikuti Kelurahan Kareko dengan 642 individu. Pada Kelurahan Batu Lubang ditemukan berjumlah 518 individu. Berdasarkan habitat yang ditempatinya, ikan capungan Pterapogon kauderni banyak ditemukan pada habitat Bulu Babi terutama pada lokasi Kelurahan Mawali (829 individu) dan Batu Lubang (476 individu) diikuti dengan Kelurahan Kareko (214 individu).

Berdasakan analisis kepadatan relatif (persentase), ikan capungan Pterapogon kauderni di pesisir pantai Selat Lembeh bagian Timur terbanyak ada pada mikrohabitat bulu babi. Pada kelurahan Batu Lubang presentase kepadatan relatif mikrohabitat bulu babi merupakan yang tertinggi yaitu 91.89 $\%$, dan diikuti dengan kelurahan Mawali sebesar $90.01 \%$ dan kelurahan Kareko sebesar $33.33 \%$.

Kepadatan individu ikan capungan Pterapogon kauderni di Selat Lembeh bagian Timur bervariasi untuk setiap lokasi, namun demikian kepadatan individu per $\mathrm{Ha}$ tertinggi ditemukan di Kelurahan Mawali (492.51 ind./Ha) diikuti kelurahan Kareko (442.76 ind./Ha). Kondisi ini pada kelurahan Batu Lubang (304.71 ind/Ha) tidaklah jauh berbeda. 
Berdasarkan kedalaman, pada umumnya ikan capungan Pterapogon kauderni di Selat Lembeh bagian Timur ditemukan di kedalaman $1-5$ meter. Kecenderungan yang terjadi adalah distribusi ikan capungan Pterapogon kauderni akan semakin sedikit dengan bertambahnya kedalaman. Gambaran distribusi berdasarkan kedalaman ini relative sama dengan distribusi di beberapa lokasi lainnya, terutama di perairan Banggai kepulauan, Sulawesi Tengah.
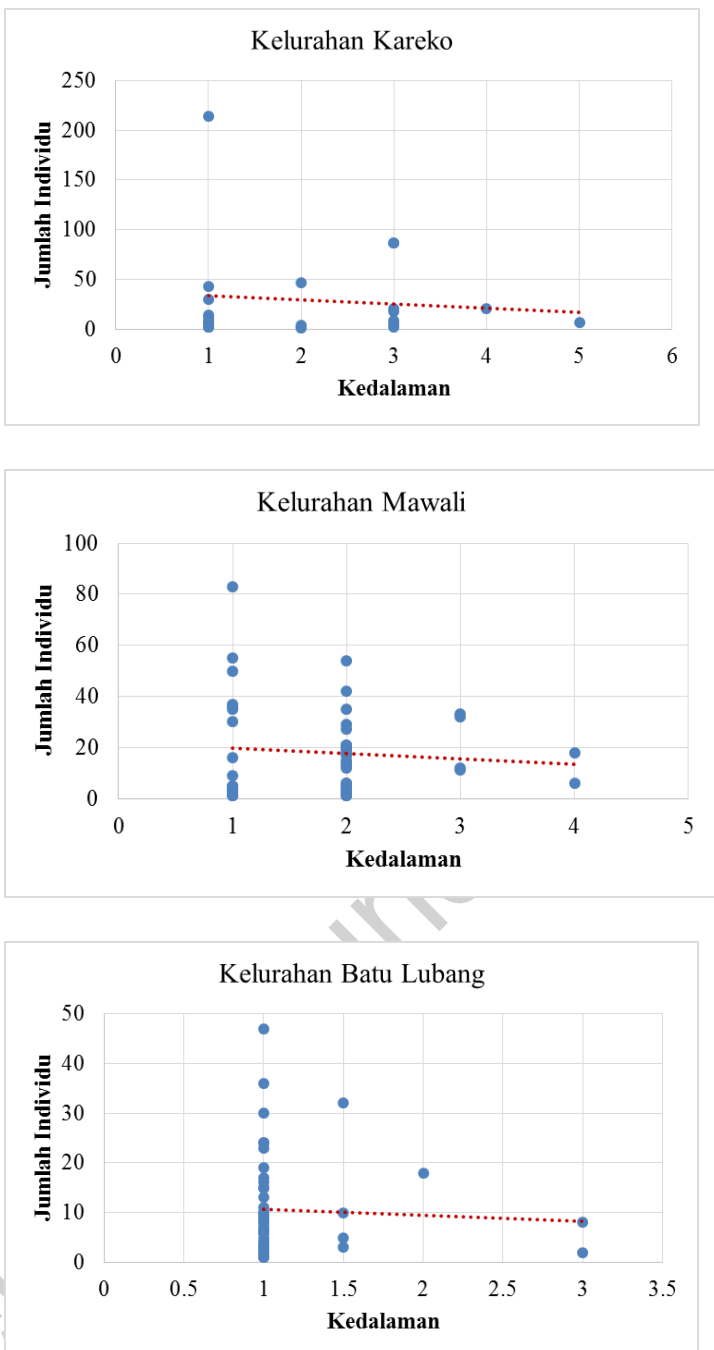

Gambar Distribusi ikan capungan Pterapogon kauderni di Selat Lembeh bagian Timur berdasarkan kedalaman.

\section{KESIMPULAN}

1. Dilihat dari hasil penelitian yang menunjukan bahwa kondisi lingkungan di Selat Lembeh baik dan sangat mendukung dalam perkembangan ikan capungan Pterapogon kauderni ini.

2. Ikan capungan Pterapogon kauderni paling banyak ditemukan di kelurahan Mawali, Selat Lembeh bagian Timur. Sebagian besar ikan ini hidup berkelompok menempati duri-duri dari bulu babi (Diadema $s p)$, dan sebagian kecil hidup berasosiasi dengan anemon. Namun tidak hanya pada kedua habitat itu saja, capungan juga ditemukan pada habitat karang bercabang, pasir/hancuran karang, kaleng, sponge, karang folios, dengan substrat yang paling banyak ditemui ialah pasir dan hancuran karang. Pterapogon kauderni pada Selat Lembeh bagian Timur hidup pada kedalaman 1 hingga $5 \mathrm{~m}$.

3. Kepadatan relative teringgi ada di kelurahan Mawali pada mikro habitat bulu babi

4. Kepadatan individu ikan capungan Pterapogon kauderni persatuan luas tertinggi ada di kelurahan Mawali.

\section{Saran}

Penelitian ini lebih banyak mengkaji tentang aspek ekologi dari ikan Pterapogon kauderni. Untuk itu diharapkan kedepannya, dilakukan penelitian yang lebih lanjut tentang aspek biologinya, seperti reproduksi, kebiasaan makan. 


\section{DAFTAR PUSTAKA}

Adrim M dan Fahmi, 2010. Panduan penelitian untuk ikan laut. Pusat penelitian dan oseanografi- LIPI. Jakarta

Allen. G.R dan Steene, 1995. Notes On The Ecology And Behavior Of The Indonesia Cardinal fish (Apogonidae) Pterapogon kauderni Koumans. Revue fr, Aquriol, 22(1-2); (7-9)

Aziz A. 1994a. Tingkah laku bulu babi di padang lamun. Oseana19(4): 35-43

DKP Banggai dan LP3L Talinti, 2006. Banggai cardinal fish (BCF) ikan hias asli Indonesia. Majalah triwulan unihaz

Hopkins Steve, Ako Harry, Tamaru Clyde S. 2005. Manual of production of the Banggai Cardinalfish, Pterapogon kauderni, in Hawai.

Kay, R. dan Alder, J. 1999. Coastal Management and Planning. E \& FN SPON. New York

Makatipu Petrus C, 2007. Mengenal ikan hias Capungan Banggai (Pterapogon kauderni). Oseana volume XXXII no. 3.

Nelson J. S, 1994. Fishes of the world. Third edition. Jhon Wiley and sons, Inc. New York. 600 p. (dalam Hopkis Steve et al, 2005)

Ndobe S. 2011. Pertumbuhan ikan hias Banggai Cardinalfish (Pterapogon kauderni) pada media pemeliharaan salinitas yang berbeda. ISSN 19795971

Nurhuda H.S, 2013. Banggai Cardinal Fish. Aqueros. Blogspot
Prihatiningsih dan Hartati.S.T, 2012.

Biologi Reproduksi dan

Kebiasaan Makan Ikan

Banggai Cardinal (Pteraogon

kauderni, Koumans 1933) di

Perairan Banggai Kepulauan.

Bawal Widya Riset Perikanan

Tangkap vol.4 1 April 2012 hal. 6.

Reksoadmodjo, 2007. Satistika Untuk Psikologi dan Pendidikan. Bandung : Refika Aditama

Soegianto Agoes, 1994. Ekologi Kuantitatif Metode Analisis Populasi dan Komunitas. Usaha Nasional. SurabayaIndonesia

Tullock.J, Michael. 1999. Aquarium Frontiers Envirovmental Aquaritest (www.animalnetwork.com)

Vagelli A.A dan Erdmann M.V, 2002. First comprehensive ecological survey of the Banggai Cardinal Fish, Pterapogon kauderni. Environmental Biology of Fishes, 63.

Vagelli A.A, 2005. The Banggai Conservatiom Project. Working for the creation of a network of small marine sanctuaries in the Banggai Archipelago, Indonesia. Communique. Am. Zoo \& Aquarium Assoc. July 2005 :47-48. 


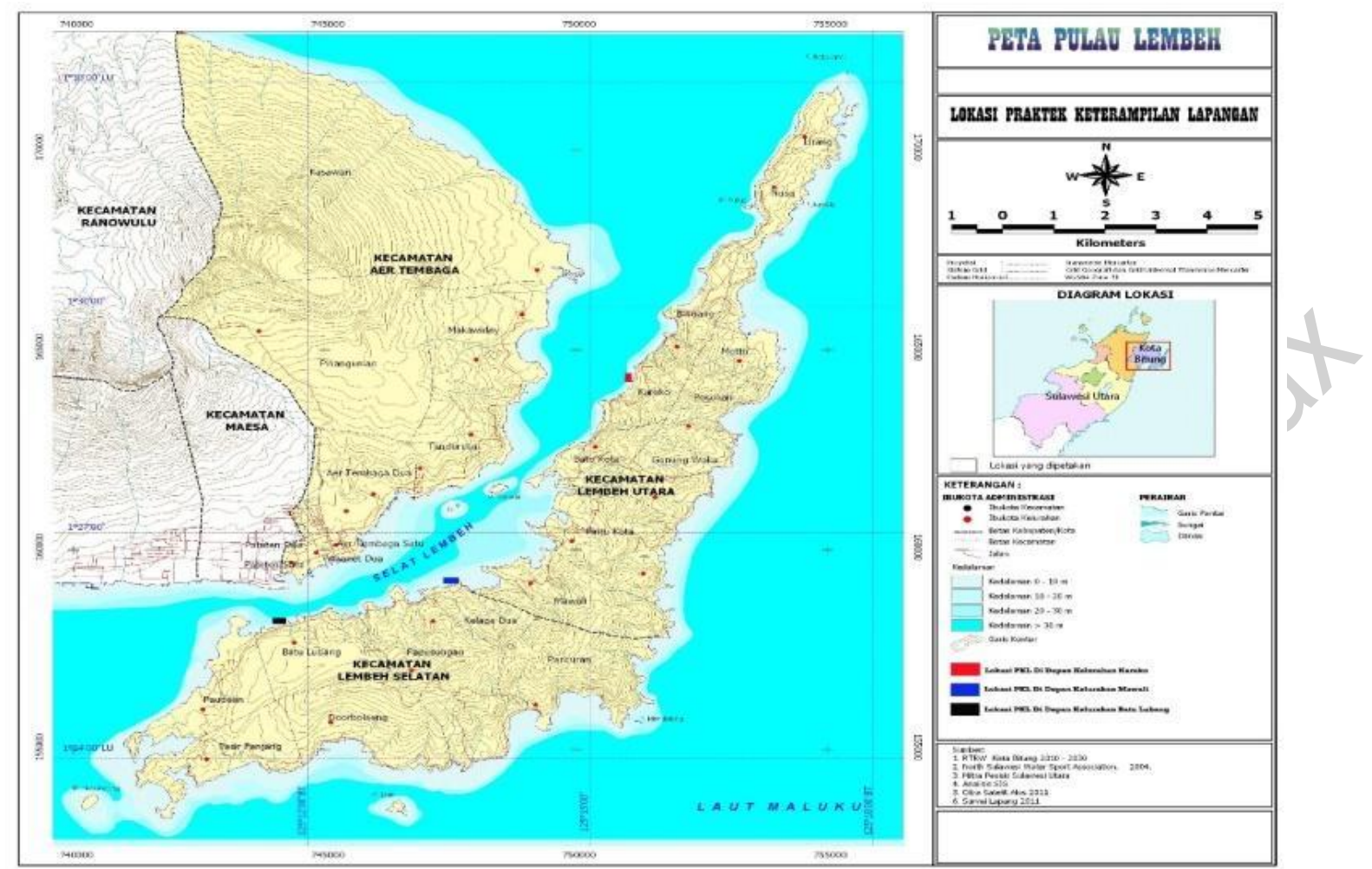

Gambar 1.Lokasi Penelitian 